\title{
The Psychotherapeutic Relationship in Massage Therapy
}

\author{
Timothy Clark, MCounsPsychthrpy, DipRemMassage \\ Time and Space Therapies, Murrumbeena, Victoria, Australia
}

Background: Psychotherapy and massage therapy (MT) are effective treatments for depression and anxiety. Little is certain about the mechanisms behind these effects in MT, but in psychotherapy they are attributed to a combination of common and specific factors, at the heart of which lies the therapeutic relationship. Research into the psychotherapeutic relationship in MT, therefore, may advance understanding of its impact on depression and anxiety.

Purpose: This research seeks to elucidate the components of the psychotherapeutic relationship in MT to inform training, research, and practice.

Participants \& Setting: Two participants-a therapist and a client_from Melbourne, Australia.

Research Design: A qualitative methodology was employed whereby one therapeutic relationship was observed over the course of three massage treatments. After each treatment, the participants commentated recordings of the sessions. The recordings were transcribed and analyzed using Interpretative Phenomenological Analysis (IPA) and Conversation Analysis (CA). Themes and subthemes were extracted from the analysis.

Results: Four overarching themes emerged: Separateness, Pleasure, Merging, and Internalization. Separateness is associated with the subthemes of Boundaries, Performance of Roles, and Power. Pleasure is associated with the subthemes of Safety, Comfort and Communication. Merging is associated with the subthemes of Contact and Empathy. Internalization has no subthemes.

Conclusions: The results suggest that a clearer conceptualization of the therapeutic relationship in MT may help massage therapists more purposefully treat depressed and anxious clients. A greater emphasis on self-awareness in the professional development of massage therapists may also foster this. Additionally, the role of pleasure in the therapeutic relationship in MT warrants closer examination.

KEY WORDS: therapeutic relationship; massage therapy; psychotherapy; phenomenology; selfawareness; pleasure

\section{INTRODUCTION}

While massage therapists typically treat with a biomechanical focus, ${ }^{(1)}$ a substantial body of evidence suggests that massage therapy (MT) can help to address psychological problems, especially depression and anxiety. ${ }^{(2)}$ The mechanisms behind the psychotherapeutic effects of MT are still unclear, (3) so it may be helpful to apply to MT the principles of psychotherapy, ${ }^{(2)}$ where the mechanisms of change are better understood. The current research aims, therefore, to identify psychotherapeutic elements of the therapist-client relationship in MT. It is based on the premise that, if massage practitioners have a better idea of what exists in the therapeutic relationship, they will be better able to apply what works in the relationship. This knowledge may have implications for how massage therapists relate to their clients and address clients' psychological problems, especially depression and anxiety, which are already known to be responsive to $\mathrm{MT}$.

The efficacy of psychotherapy for a variety of psychological conditions, including depression and anxiety, is now accepted by the American Psychological Association $^{(4)}$ and supported by a well-established literature. Wampold ${ }^{(5)}$ cites a mean treatment effect size of .80, which implies that an average client of psychotherapy is "better off than about $79 \%$ of untreated clients" (p. 55). By comparison, the widely cited meta-analysis by Moyer et al. ${ }^{(2)}$ suggests that the average recipient of MT experiences a reduction of trait (or characterological) anxiety greater than $77 \%$ of people who do not receive $\mathrm{MT}$, and a reduction of depression greater than $73 \%$.

While a vast array of psychotherapeutic modalities_-such as mindfulness-based, psychodynamic, client-centred and existential approaches-conceptualize the change process, no single mechanism or modality has been proven to hold the key to change. Change is attributable instead to a combination of modality-specific and cross-modality common factors. ${ }^{(6,7)}$ The trans-theoretical, contextual model of change, formulated by Wampold and Imel, ${ }^{(8)}$ helpfully integrates aspects of many theories while emphasizing the importance of the therapeutic context. It suggests that the common factors (including the 'real 
relationship' and expectation) lead to better quality of life, whereas the specific factors (form of treatment, tasks and actions) reduce symptoms, but that none of this occurs without a bond based on mutual trust, understanding, and a recognition of the expertise that each person brings to the encounter. Psychotherapy and massage therapy are similar in some aspects of this contextual model of change, giving rise to the possibility that a more deliberate application to MT of psychotherapeutic principles may elucidate the mechanisms behind MT's mood-changing effects.

A search of psychological and medical databases (Psychology and Behavioral Sciences Collection, PsycINFO, PsycARTICLES, MEDLINE Complete, and ProQuest) yielded only one piece of research specifically addressing the nature of the psychotherapeutic relationship in MT. Moyer's ${ }^{(9)}$ dissertation suggests that greater reductions in psychological distress, which may include symptoms of depression and anxiety, can be effected by massage therapy in which talk is restricted and the therapeutic bond is strong. The current research sought, therefore, to categorize the elements of this bond.

\section{METHODS}

All data collection was conducted by the researcher, a male with a Diploma of Remedial Massage, who had been working for about three years as a remedial massage therapist. Three massage treatments by one therapist ("the Therapist") to one recipient ("the Client") were videotaped at the Therapist's home studio. Immediately after each treatment session, both the Therapist and the Client viewed the video recording in full and recorded commentaries about their experience. Questionnaires were issued to further guide the participants' commentaries, but their written responses were not analyzed and no repeat interviews were carried out. A detailed description of the procedures and tools used for data collection are contained in Appendix A.

The small sample size $(n=1$, as there is one relationship under investigation) is supported by the analytical method used, Interpretative Phenomenological Analysis (IPA). ${ }^{(10)}$ Single-subject case studies, while not common, are ideally suited to allow for the depth of analysis required when using IPA because the focus is particular rather than universal. ${ }^{(11)}$ Furthermore, $n$ $=1$ studies are increasingly encouraged. ${ }^{12}$ Purposive sampling was used; both the Therapist and the Client were recruited by email from the researcher's personal contacts to allow for selection of reflective participants who were comfortable with the protocol of filmed massages. Both were required to be over 18 years of age. Informed consent was obtained following provision of Plain Language Information Statements regarding the aims and methods of the research. The impact of variables, such as gender and nationality, is outside the scope of this research, so these factors did not determine selection of participants. To preserve ecological validity and encourage unbiased responses, it was necessary to select two participants with no prior relationship and little likelihood of contact following the research. No other researchers were involved in data collection.

The Client was the second person approached to fill the role; the first could not participate due to other commitments. The Client, a female and a social acquaintance of the researcher, was able to select the gender of her therapist. The Therapist, also female, was the second therapist approached directly by the researcher; the first was not available to participate. The Therapist had attended massage school with the researcher and was a fully qualified, registered, and insured remedial massage therapist.

The treatment sessions were transcribed using conventions of Conversation Analysis (CA), ${ }^{(13)}$ which requires notation of prosodic features of dialogue, including pitch, volume, pace, and breathing. A list of conventions used in the transcripts is provided in Table 1. The durations of the treatment sessions are provided in Appendix B. The commentaries were transcribed close to verbatim. The transcriptions, along with a listing of the massage techniques administered, were tabulated to allow for easy crossreferencing between components. The results were analyzed by the researcher using conventions of IPA, which typically involves what is called a "double hermeneutic"; $(10,11)$ that is, there are two levels of interpretation: the participants interpret their own behaviour, and the researcher interprets the latent content of what the participants say, giving evidence to support that interpretation.

The CA transcripts and commentaries were placed into an Excel spreadsheet for tabulation to allow for easy cross-referencing between what was said in the

TABLE 1. Conventions of Conversation Analysis

\begin{tabular}{lc}
\hline \multicolumn{1}{c}{ Symbol } & Meaning \\
\hline[ & Beginning of an overlapping utterance \\
[ & End of an overlapping utterance \\
A stopping fall in tone
\end{tabular}


sessions and what both the Client and Therapist said about it in the commentaries. A column was added listing any important actions that occurred, such as massage strokes, handshakes or gestures, which would not be evident from the dialogue or commentaries. Space on the right-hand margin was left for the researcher's field notes. The researcher colour-coded the field notes according to themes, though some were linked to more than one theme, and then ordered them to reflect roughly the chronological development of the psychotherapeutic relationship in MT.

This approach combines elements of what Braun and Clarke ${ }^{(14)}$ label the 'inductive' and 'theoretical' methods of thematic analysis. Although the data were approached with an open mind (an inductive approach), psychotherapeutic theory invariably guided the researcher's interpretation of themes and subthemes. This approach allowed the researcher to both observe the relationship without prejudice and to use existing theories to bring a structure to the findings. Data saturation was not discussed.

Participants did not provide feedback on the transcripts or on the findings, but were given access to the completed research. The research proposal was approved by the Human Research Ethics Committee of the researcher's institution.

\section{RESULTS}

\section{Session Summaries}

A brief, general summary of each session is included to give context to the thematic analysis. A detailed breakdown of the timings of each session, the massage techniques used, and topics of conversation are provided in Appendix B.

Session 1 is characterized by the establishment of boundaries, roles and safety, the fulfillment of social expectations, and discovery of some common ground between the Client and the Therapist. The tone of exchanges, while warm and light, is slightly more guarded than in later sessions. The Therapist, by her own admission, was nervous about being filmed, which may explain the unorthodox aspects of the sequence, such as starting with firm pressure on the lower back, and treating only one hand.

Session 2 is characterized by negotiation of boundaries, reduced formality, and the development of the Client's somatic awareness. The session is dominated by conversation, with the only significant moments of silence arising around the midpoint, and again near the end. The Therapist's increased comfort with being filmed seems to be reflected in the sequence of strokes which include more petrissage to bridge effleurage and frictions.

Session 3 is characterized by the participants' greater sense of security about boundaries and selfdisclosure, and more periods of prolonged silence than either of the other sessions. The Client relates details about family and intimate relationships, and both topics elicit strong reactions from the Therapist. The strong emphasis on frictions in the stroke sequence suggests the Therapist's confidence with the Client's preferred level of pressure.

\section{Thematic Analysis}

The analysis yielded four themes and eight subthemes, compiled in Table 2. They suggest a taxonomy of the components of the psychotherapeutic relationship within $\mathrm{MT}$, and a roughly chronological process by which the therapeutic relationship may catalyze change. What follows is an explication of the themes and subthemes extracted from the analysis.

\section{Theme 1: Separateness}

The essential separateness of the Client and Therapist - that is, the physical and psychological distance between them - is most pronounced at the beginning of the treatment process and remains throughout, even as other aspects of the relationship reduce the participants' perception of this distance.

\section{1: Boundaries}

The Therapist bears most responsibility for monitoring symbolic boundaries. Her choice of what she terms a "safe subject" for conversation at the start of each treatment is aimed at helping the Client to relax and distract her from any discomfort caused by the application of pressure, but it also protects the Therapist's professional boundary. The Therapist seems uneasy when the discussion turns to her personal life, as in the following exchange:

Client: did you get up to much?

Therapist: .hhh $\uparrow$ me oh hhh $\uparrow$ y'know just plodding along hhh-heh heh heh

(5.0)

jus-it's s'posed to be like twenty-seven or something today too

TABLE 2. Themes and Subthemes of the Psychotherapeutic Relationship in Massage Therapy

\begin{tabular}{cc}
\hline \multicolumn{1}{c}{ Theme } & Subtheme \\
\hline 1.0 Separateness & 1.1 Boundaries \\
& 1.2 Performance of roles \\
& 1.3 Power \\
2.0 Pleasure & 2.1 Safety \\
& 2.2 Comfort \\
3.0 Merging & 2.3 Communication \\
& 3.1 Contact \\
4.0 Internalization & 3.2 Empathy
\end{tabular}


Her commentary on this moment reveals her choice to shift the focus away from herself.

Therapist: She's asking me how I'm doing and [...] I've just neatly changed the subject there. I've just flipped it back, to let her relax and talk about herself more, and keep the focus on her...

In this way, maintaining professional boundaries reinforces the Client's primacy as the target of therapeutic attention but also allows the Therapist to feel safe.

\section{2: Performance of roles}

The performance of roles serves as a framework for safe treatment, within which lies room for negotiation and personalization. The roles bring consistency, structure, and familiarity, which help to contain the vulnerability that both participants can feel.

The Client and Therapist know they each have a role to play. The Client is generally deferent and passive, allows the Therapist to direct proceedings, and provides information upon request. The Therapist utilizes elements of stagecraft in portraying her role: she is neatly groomed, carries a clipboard, displays her framed qualifications, and wears a uniform with embroidered logo. These cast a deliberate impression on the Client, defining a fixed, stable identity for the Therapist. The Client's responses to the Therapist's performance change across treatments. Her early impressions of the Therapist, while overwhelmingly positive, bear signs of uncertainty:

Client:...she just genuinely cared about me. That's how I felt anyways. If she didn't she was good at pretending to, but I think she did.

By Session 3, the Client's uncertainty remains, but she speaks of it in a more resigned tone, suggesting awareness that this performance of roles can help relationships to thrive:

Client:...she must have so many clients, so she must be really good at pretending to care, but if she is pretending to care, she's really good at it, if that makes sense.

Like an audience member at a play, the Client's suspension of disbelief is in service of a higher purpose. She comes to tolerate and even appreciate the uncertainty of the relationship, which may help her to reframe her attitude to uncertainty, a central goal of many forms of psychotherapy.

\section{3: Power}

The relationship in MT has parallels with a caregiver-infant relationship because, like a parent, the Therapist must anticipate the Client's needs and avoid doing harm. And like a child, the Client's power is bound up in the social systems - economic, legal, and cultural-designed to support vulnerable people. In this way, a positive massage experience may reinforce for both participants a sense of trust in other people and the community at large.

\section{Theme 2: Pleasure}

The Therapist's facilitation of a pleasurable experience for the Client determines how well their separateness can be bridged. Indeed, the Client's enjoyment of the massage seems vastly more important to her than symptom reduction. This is where MT seems to deviate most obviously from psychotherapy. The provision of pleasure in psychotherapy may be required only as far as it permits uninterrupted engagement with the client. In MT, it is possible that facilitating pleasure may actually be a key function of the therapist's role.

\section{1: Safety}

Once trust is established, the massage environment and therapeutic relationship become something of a safe haven for the Client, a space away from the pressures and uncertainties of the outside world. With her eyes covered, the Client feels like she is in her "own bubble". This "bubble" grows to include the Therapist, and a number of exchanges are infused with an 'us against the world' mentality:

Client: yeh (1.0) people are just mean

Therapist: yeah hhh heh

Client: they're just they're so mean

Therapist: yeah yeah you'd think they'd be er nicer

Client:

[this time of year and [yeah]

\section{2: Comfort}

Physical warmth is frequently cited by both participants as a source of comfort. The Therapist regularly checks the ambient temperature, heats the table with an electric blanket, and warms the draping towels before use. Her persona is similarly warm. The Client describes the Therapist as "bubbly", "dependable", "down-to-earth", and "someone that [she] would be friends with". The Therapist's ability to present herself as simultaneously humble and professionally capable seems to be central in creating these impressions.

The Therapist also helps the Client to feel that she is not being personally judged, such as in this moment early in the relationship:

Client: I'm Indian, so I sweat and it smells like butter chicken

$$
\text { [on my arms, so] }
$$

Therapist: [that's alright darling]

Therapist: That's fine you know then I'll I'll just feel

like I'm at the local restaurant

In this instance, the Therapist's use of humour diffuses the Client's concerns and her use of the 
affectionate "darling" suggests the unconditionally forgiving tone of an adult caregiver reassuring a child. This unconditional positive regard is one of Rogers' "necessary and sufficient conditions"( $(15,16)$ for therapeutic change.

\section{3: Communication}

The Client is able to experience pleasure through both tactile and verbal communication, but the manner in which each mode generates the Client's pleasure is different. The Client initially worries about the etiquette around conversation but, as her comfort level with the Therapist grows, her anxiety reduces and she converses freely. In her commentary, the Client states that her ideas about talking during MT are shifted as a result of the Therapist's talk-laden treatment style:

Client: ...I used to think I was like [...] 'You're here to like get a massage and relax and fall asleep' but, talking to her, I was like letting go of things cos I was just telling her and I was just venting...

Close analysis of her comments points to a more deep-seated ambivalence on the issue:

Client: She was constantly telling me what she was going to do and how it might feel or how the pressure was so I felt like she constantly wanted to know [...] and she was constantly telling me [...] She was very talkative and that was a good thing because she was constantly asking me about my life and about my dog or anything like that, and making conversation, like making me talk.

While her overall tone remains positive and affirming of the Therapist, her repetition of "constantly" hints at unspoken frustration with the regularity of the Therapist's enquiries, the pejorative "talkative" is defensively smoothed over, and "making me talk" suggests her sense of being pressed, rather than acting out of free will.

Tactile communication contributes more directly to the Client's experience of pleasure. The many variations on "that felt nice" peppered throughout the Client's commentary suggest that what stays most with the Client after treatment is less the content of conversation and more the sensations experienced while talk occurs. This suggests an unconscious acceptance of the messages of care and comfort that the Therapist knowingly communicates through her touch. In her commentaries, the Therapist frequently offers verbal translations of her wordless actions, such as:

Therapist: ...when you're in under the head and you're holding, that's communicating that you're supporting by the particular hold that you've got...

The Client's reflection on the same moment is not a corresponding, 'Thank you, I feel supported,' but an assessment that it "felt really good." In this way, the Client's experience of pleasure is mediated by the Therapist's ability to communicate care through touch.

\section{Theme 3: Merging}

Through the Therapist's facilitation of a pleasurable experience for the Client, a kind of metaphorical merging occurs, whereby the two entities meet and, despite retaining their essential forms, blur and breach the boundaries that separate them. This merging contains numerous elements from psychotherapy, including transference and countertransference, ${ }^{(17)}$ loving interaction, ${ }^{(18)}$ attunement, ${ }^{(19)}$ and relatedness, ${ }^{(20)}$ but the addition of the physical dimension seems to demand a more concrete term. It is important also to distinguish 'merging' from psychotherapeutic terms that may sound similar-such as 'fusion', 'enmeshment', even 'attachment' - but carry many different connotations in this context.

\section{1: Contact}

At the start of each treatment, before undraping the Client and before any massage occurs, the Therapist deliberately places two firm hands on the Client's back and, as much as possible, keeps one hand on the Client throughout the treatment. As well as reassuring the Client of the Therapist's whereabouts while face-down, this serves the more poetic function of temporarily merging two individual entities together, albeit symbolically. It is as if the Client disconnects from her motoric brain and the Therapist assumes responsibility for it. This extends to adjusting the Client's position on the table, lifting her limbs to massage them, and moving her muscles in ways she would not be able to on her own. In many ways, the merging that occurs in MT aligns with Spinelli's ${ }^{(20)}$ notion of 'worlding': social roles become meaningless, boundaries become ambiguous, the Client is not required to be or do any thing, as the experience of pleasure takes the Client out of the realm of the concrete into a place where words are not necessary or, bearing in mind the Client's struggle to qualify her experience of the massage, possible.

The Therapist also maintains contact by talking, especially by checking in with the Client about her level of comfort and her window of tolerance for pain. As well as affording the Therapist a better understanding of the Client's experience, which fosters empathy, it brings the Client a direct, conscious experience of connection:

Client: I felt really connected to her when she would ask me about the pressure and [...] when she would tell me what she was going to do and how it might feel.

Later in the relationship, this feeling of connection is extended when the Therapist no longer needs to enquire as much about the pressure: 
Client: I felt connected to her when she already knew what areas I was gonna be sore in [...] even though I didn't know I was going to be sore in that area.

This seems to be received by the Client as evidence of a strong psychic union, as if the Therapist knows the Client's body better than she does herself.

The kind of metaphysical 'melting' of the boundaries between the Therapist and Client is further suggested by the Therapist's use of metaphor, such as "massaging... ears" to imply talk, and "my hands are doing the talking [and] listening and observing", wherein she ignores the laws of physics and biology to conceptualize her method of connecting to the Client. The Client, too, gives voice to the messages sent by the Therapist's hands:

Client: ....at the end of every massage, she puts her hands over my eyes for like a good twenty seconds. Just be like, “Ah! This is the end. It's all over. Enjoy yourself. Calm down."

This move from the real to the imaginary, from the scientific to the intuitive, characterizes the merging process.

\section{2: Empathy}

Empathy and pleasure work in a cycle in this relationship. At first, they are facilitated only by the Therapist. As the sessions progress, the Client becomes more curious and interested in the Therapist's experience, the Therapist becomes less guarded, and empathy flows more freely between the two participants. Accordingly, when the Therapist's attempts to empathize are affected by countertransference, ruptures occur and may shift the dynamic of the relationship, even to the point of reversing roles.

In Session 3, the Therapist empathizes openly with the Client, who is frustrated with her older brother for not taking responsibility for the dog they bought together. But soon, the Therapist's disdain for the Client's brother intensifies beyond that of the Client and her language becomes belittling, even dehumanizing:

Therapist: hhh-heh heh heh heh so you're looking after two

Client: yeah [it's like what's the point]

Therapist: [er children the dog]

Therapist: and your brother heh heh heh

Therapist: maybe you could train them together maybe you could take him to like hhh back to puppy preschool

While the Client is critical of her brother's actions, she does not go as far as dehumanizing him until invited to by the Therapist, who seems motivated by sympathy for the dog, rather than empathy with the Client. The Therapist's anger is further suggested by her disproportionately lengthy application of highpressure strokes to the Client's back. This appears to be an example of countertransference, where the Therapist's own experiences and frame of reference unconsciously shape her response to the Client. As a result of what appears to be a strong attachment relationship to dogs, the Therapist acts more out of concern for the dog than for the Client, which seems to elicit guilt from the Client:

\section{Client: yeah just didn't think about it like that [X X] Therapist: \\ [yeah]}

(35.0)

Therapist: it's like we watch this space hey?

Client: mm-hm

During the 35-second silence, the Therapist appears to linger on her frustration, her unconditional positive regard for the Client wavering for the first time, and the empathic connection falters. Only when the Client is able to add some positives to her depiction of her brother is the rupture repaired.

A few times throughout the sessions, the Therapist appears to experience a countertransference reaction, most notably in response to the Client's anecdotes about her dog. The Therapist's pervasive interest in the Client's dog and her disdain for the brother's apparent neglect, along with her disclosures to the Client that a film about a dying dog made her "bawl" and that, growing up, she would "bring home every stray dog", all point towards a strong attachment relationship to dogs. For the most part, this does not threaten the relationship, but a potential rupture arises when the Therapist's emotional response exceeds that of the Client. This suggests that the Therapist is responding to her own past experiences rather than the specific experience of the Client, which affects not only the tone of conversation but the quality of touch that the Therapist applies.

\section{Theme 4: Internalization}

The merging process seems to allow the Client to absorb some of the Therapist's knowledge, which sharpens the Client's awareness of her body and how it moves. In the first session, the Therapist maximizes the placebo effect by suggesting to the Client that massage therapists "always have a secret way of finding [a client's sore] points", and the Client verifies this:

Client: I didn't know that I was sore in those areas until she like, cos she asked me before and I said, "I don't think so" but when she actually started massaging me then I was like, "Oh that is kinda sore."

The Client comes to expect that the Therapist will continue to discover areas of pain previously 
outside awareness. This expectation and its fulfillment by the Therapist feeds the Client's experience of pleasure and her sense that the Therapist truly understands her needs, which in turn seems to fuel the Client's curiosity about the Therapist's clinical reasoning. Because they have 'merged', curiosity about the Therapist is also curiosity about self, which seems to be something the Therapist consciously fosters. She seeks to increase the Client's self-awareness by educating her about how her habits and activities may be contributing to patterns of dysfunction.

At the end of Session 3, the Therapist explains the Client's neck and shoulder pain by gesturing to her own neck and shoulder, as well as those of the Client, as if their features were interchangeable. The mutual identification continues as she demonstrates to the Client a technique for self-massage, inviting the Client to mirror her actions. The merging process thereby may facilitate the Client's ability to treat herself the way the Therapist treats her, to show herself the same degree of care and warmth, to nurture and affirm herself, but also to observe herself without judgment, and to remain curious about herself. The research did not examine the extent of this internalization, how long the process of internalization takes, or how it affects the Client on a day-to-day basis. This may be a starting point for future research.

Kleinian psychoanalytic principles of projection and introjection deriving from early experiences with the 'good' breast and 'bad' breast ${ }^{(21)}$ lend further weight to the idea that internalization occurs in MT, and are suggested by the Client's remarks near the end of Session 3:

Client: She was kinda like mom-like, you know how moms have that natural, nurturing instinct, or some do anyways. That's what she was like.

The infant-caregiver comparison is further borne out in the way the Client rejects any suggestions that the Therapist may not be completely attuned to the Client's needs. She lavishes praise on the Therapist's strengths, but glosses over a number of uncomfortable moments, 'taking in' the good and rejecting the bad. The Therapist's language, too, with its "blankie", "puppy" and "loosey goosey", reinforces the comparison, as does her wiping away of excess oil, upon which she reflects:

Therapist: I'm just wiping off the excess and...it's like the cloth when they swaddle babies, the extra support of the cloth and it's that cloth against the body and also that hand on top of it is a very caring movement...

Further exploration of how infant-caregiver roles play out in MT may help to shed more light on how the relationship works.

\section{DISCUSSION}

As might be expected with research of this type and scale, the findings are not generalizable, and may be of greatest utility as springboards for further research across qualitative and quantitative domains. In shaping future approaches, Wampold and Imel's contextual model ${ }^{(8)}$ may provide a useful framework for conceptualizing psychotherapeutic processes in MT, largely because the therapeutic relationship underpins its every aspect. Its central tenets of trust, understanding, and expertise are echoed in the themes and subthemes identified in this research.

In addition to these common factors, an awareness of psychotherapeutic modality-specific factors may offer MT researchers useful paradigms, and allow massage therapists to conceptualize a wider range of client problems and customize their treatment to clients' specific needs and communication styles. Approaches invoked in the analysis include mindfulness, psychoanalytic, and client-centred and existential principles, but numerous others may be apposite.

That the Client in this research showed signs of internalizing the caring, maternal figure of the Therapist suggests that the relationship in MT can be psychotherapeutic, even if the therapist does not intend it to be. There may be no need, therefore, for a formalized integration of MT and psychotherapy. As Barnett \& Shale ${ }^{(22)}$ imply, the potential for boundary violations and the risks associated with dual relationships render highly problematic an approach where MT and psychotherapy are given by the same practitioner. What may be more helpful is a psychotherapeutically informed approach to MT, in which the therapist is highly selfaware, their role is clearly defined, and the client has a clear understanding of the purpose and relevance of any interventions used that may be seen to be outside the practitioner's scope of practice, and furthermore permits their use explicitly and autonomously.

The results also suggest that therapists' awareness of their own psychology and behavioural patterns may help them to avoid rupturing their relationships with clients. Because the act of giving a massage does not permit therapists to give their full attention to the content of conversation during treatment, the likelihood of unconscious material rupturing the relationship in MT may be greater than in purely talk-based therapies. The therapeutic use of rupture-repair, which is commonplace in psychotherapy, ${ }^{(23)}$ may be difficult to implement in MT, as evinced in this study by the Therapist's failure to initiate this repair herself, although the data did not make clear how this failure impacted the Client, if at all. This is in line with Moyer's ${ }^{(9)}$ finding that talk-restricted, high-therapeutic bond conditions are optimal for reducing psychological distress. Future research examining the effects of the therapeutic relationship in MT across time could help address questions around the therapeutic use of talk in MT, especially with depressed and anxious clients. 
Additionally, future research could examine how clients' enjoyment of massage impacts upon its benefits, how clients perceive those benefits, and how central the client's experience of pleasure may be to MT's effects on anxiety and depression. It is understandable that therapists and clients might be wary of enjoying massage because of cultural discourses on sexual morality, harassment and abuse, and the sexualization of touch in many cultures. To combat this, it may be necessary for therapists to have a moral compass that is as finely tuned as that of a psychotherapist, fostered through rigorous ethics training. The model of the therapeutic relationship offered here suggests that respect for boundaries and the provision of safety are cornerstones of the therapeutic relationship in MT. As long as practitioners work within their ethical boundaries, professional health care and pleasure need not be mutually exclusive.

\section{Limitations}

The very small sample size $(n=1)$ negates any generalizability of the findings. The participants' awareness of the research topic may have positioned them to offer the types of responses they thought could be most beneficial, rather than permitting full candour. Additionally, no attempt was made to account for factors such as the participants' emotions prior to the sessions, their attitudes to massage, ${ }^{(24)}$ their personal, psychological and cultural characteristics, or their personal connections to the researcher, all of which may have influenced their behaviour and responses. The presence of recording equipment in the room impacted upon the Therapist's level of comfort, but this impact seemed to reduce over time. Further research in a similar vein may help to explain how the relationship develops over longer periods of time, between different pairings and in different environments.

\section{CONCLUSION}

The results of this study suggest that massage therapists who have greater self-awareness may be able to better influence how clients respond to them and thereby reduce their clients' distress. The importance of pleasure in MT as a catalyst for the client's internalization of a caring figure warrants further study, as does the role of psychotherapeutic processes in MT in general.

\section{ACKNOWLEDGMENTS}

The author would like to acknowledge the contributions of Dr. Stephen Andrew, Assoc. Prof. Andrew Francis, Prof. Ben Richardson, Dr. Alastair Anderson, and the study participants.

\section{CONFLICT OF INTEREST NOTIFICATION}

The author declares there are no conflicts of interest.

\section{COPYRIGHT}

Published under the CreativeCommons AttributionNonCommercial-NoDerivs 3.0 License.

\section{REFERENCES}

1. Fortune LD, Hymel GM. Creating integrative work: a qualitative study of how massage therapists work with existing clients. J Bodywork Movement Ther. 2015;19(1):25-34.

2. Moyer CA, Rounds J, Hannum JW. A meta-analysis of massage therapy research. Psych Bull. 2004;130(1):3-18.

3. Moyer CA. Anxiety and depression. In: Dryden T, Moyer CA, eds. Massage Therapy: Integrating Research and Practice. USA: Human Kinetics; 2012:168-180.

4. Campbell LF, Norcross JC, Vasquez MJ, Kaslow NJ. Recognition of psychotherapy effectiveness: the APA resolution. Psychotherapy. 2013;50(1):98-101.

5. Wampold BE. The Great Psychotherapy Debate: Model, Methods, and Findings. Mahwah, NJ: Lawrence Erlbaum Associates; 2001.

6. Rosenzweig S. Some implicit common factors in diverse methods of psychotherapy. Am J Orthopsychiatry. 1936;6(3): 412-415.

7. Duncan BL, Miller SD, Wampold BE, Hubble MA, eds. The Heart and Soul of Change: Delivering What Works in Therapy, 2nd ed. Washington, DC: American Psychological Association; 2010.

8. Wampold BE, Imel ZE. The Great Psychotherapy Debate: the Evidence for What Makes Psychotherapy Work. New York, NY: Routledge/Taylor \& Francis Group; 2015.

9. Moyer C. Massage Therapy: an Examination of the Contextual Model ( $\mathrm{PhD}$ thesis). Champaign, IL: University of Illinois at Urbana-Champaign; 2007.

10. Smith JA, Osborn M. Interpretative phenomenological analysis. In: Smith J, ed. Qualitative Psychology: A Practical Guide to Research Methods, $2^{\text {nd }}$ ed. London, UK: Sage; 2008:53-80.

11. Pietkiewicz I, Smith JA. Praktyczny przewodnik interpretacyjnej analizy fenomenologicznej w badaniach jakościowych w psychologii [in Polish]. Czasopismo Psychologiczne. 2012;18(2):361-369.

12. Cassidy E, Reynolds F, Naylor S, De Souza L. Using interpretative phenomenological analysis to inform physiotherapy practice: an introduction with reference to the lived experience of cerebellar ataxia. Physiother Theory Pract. 2010;27(4): 263-277.

13. Schegloff EA, Jefferson G, Sacks H. The preference for self-correction in the organization of repair in conversation. Language. 1977;53(2):361-382.

14. Braun V, Clarke, V. Using thematic analysis in psychology. Qualitat Res Psychol. 2006;3(2):77-101.

15. Rogers CR. The necessary and sufficient conditions of therapeutic personality change. J Consulting Psych. 1957;21(2):95. 
16. Rogers CR. A client-centered/person-centered approach to therapy. In: Kutash I, Wolf A, eds. Psychotherapist's Casebook: Theory and Techniques in the Practice of Modern Therapies. San Francisco, CA: Jossey-Bass; 1986: 197-208.

17. McWilliams N. Psychoanalytic Diagnosis: Understanding Personality Structure in the Clinical Process, 2nd ed. New York, NY: The Guilford Press; 2011.

18. Natterson J. Psychotherapy as a Mutual Loving Process. Chevy Chase, MD: International Psychotherapy Institute; 2015.

19. Siegel DJ. The Mindful Therapist: a Clinician's Guide to Mindsight and Renewal Integration. New York, NY: WW Norton \& Company; 2010.

20. Spinelli E. Practising Existential Therapy: the Relational World, 2nd ed. London, UK: Sage Publications; 2015.

21. Klein M. Notes on some schizoid mechanisms. Int J Psychoanal. 1946;27:99-110
22. Barnett J, Shale A. The integration of Complementary and Alternative Medicine (CAM) into the practice of psychology:a vision for the future. Prof Psych: Res Pract. 2012;43(6): 576-585.

23. Safran J, Muran JC, Samstag L, Stevens C. Repairing alliance ruptures. In: Norcross JC, ed. Psychotherapy Relationships that Work: Therapist Contributions and Responsiveness to Patients. London, UK: Oxford University Press; 2002: 235-254.

24. Moyer CA, Rounds J. The Attitudes Toward Massage (ATOM) scale: reliability, validity, and associated findings. $J$ Bodywork Movement Ther. 2009;13(1):22-33.

Corresponding author: Timothy Clark, MCounsPsychthrpy, DipRemMassage, Time and Space Therapies, 16 Omama Rd., Murrumbeena, Victoria 3163, Australia

E-mail: tim@timeandspacetherapies.com.au 


\section{APPENDICES}

\section{Appendix A. Procedures and Tools Used for Data Collection}

\section{Data Collection Procedure}

1. The researcher arrives at Therapist's home studio, meets the Therapist and checks studio set-up (table access, table height, all required materials and equipment). Instructs the Therapist on camera use.

2. Set up and test recording equipment. When the Client arrives, start cameras recording.

3. The researcher greets the Client, directs her to the clinic room.

4. The Client enters studio to meet the Therapist. The Therapist completes pre-assessment, briefs the Client on (a) draping procedure and (b) clothing requirements.

a. During the massage when the Therapist is in the room and the cameras are filming, the Client is draped with towels. One towel covers the length of the body and another is placed horizontally across the Client's back. Only the area being worked on is undraped as the Therapist works on it. Any exposure of the lower buttocks, genitals, groin, pubic region, breasts or nipple would constitute a breach of the Code of Ethics of the Therapist's professional body. Areas to be worked on by the Therapist may include:

i. The back, neck, and shoulders

ii. The lower back and upper buttocks. Permission to include the upper buttocks, if necessary, will be sought by the Therapist both verbally on camera and in writing on the client history form. Towels are tucked discreetly into the Client's underwear to keep the towels from moving and protect the underwear from oil.

iii. The back of each leg-only one leg at a time.

iv. The front of each leg-only one leg at a time.

v. The abdomen-from the line of the underwear to about two inches above the navel.

vi. The upper chest, face, and scalp_- towels lowered about an inch below the clavicle.

b. The Client may leave on whatever items of clothing allow her to remain comfortable. The Client must leave on briefs but may remove her bra.
5. The Therapist leaves the Client to undress and/ or get on table, pauses cameras on way out. The Therapist informs the Client whenever she pauses or resumes filming.

6. The Therapist knocks before re-entering, restarts cameras recording.

7. The Therapist conducts massage treatment. To protect ecological validity, the type of massage administered will depend on the Therapist's training and the Client's preferences and goals as determined in collaboration with the Therapist.

8. The Therapist may turn the Client so as to be able to access the front side of the body. A turning protocol is used whereby the Therapist holds the towel down over the Client as the Client turns. The towel shields the Client from the view of the Therapist and cameras during the turn.

9. At the conclusion of the treatment, the Therapist leaves the Client to get dressed, pauses cameras on way out.

10. The Therapist knocks before re-entering, restarts cameras recording.

11. The Therapist conducts post-assessment, bids farewell to the Client, stops cameras recording. Client briefly remains outside the premises.

12. The Therapist goes to a nearby room and waits, then the Client returns to the clinic room. Both the Client and Therapist have about 15 minutes to respond to the questionnaire.

13. The researcher sets up a laptop ready to play back the video of the session for the Client, prepares video files to play from the camera's memory card, and sets up a camera with a new memory card to record the Client's commentary.

14. The researcher brings the Client in to the clinic room, starts the camera recording, starts the video playback and leaves the Client to record her commentary.

15. The researcher goes to the Therapist's room and sets up per Step 13

16. The researcher remains on the premises in a separate room.

17. The Client completes viewing and commentary, leaves the premises.

18. The Therapist completes viewing and commentary.

19. The researcher consolidates video files on a single hard drive. Video files are erased immediately from cameras and/or memory cards.

20. The researcher packs up equipment, returns all recording locations to their original state, and leaves the premises. 


\section{Questionnaires}

\section{Client Questions_-All Sessions}

- What did the therapist do or say that made you feel

$\circ$ Welcome or unwelcome?
$\circ \quad$ Understood or misunderstood?
$\circ \quad$ Heared for or not cared for?
$\circ \quad$ Optimistic or pessimistic?
$\circ \quad$ Motivated or unmotivated?

- What sources of information did you have about the therapist? (For example, words, tone, appearance, gestures, facial expressions, quality of touch, your own gut feeling). Which one(s) did you rely on most significantly?

- What did you notice about the general tone of your thoughts or your mood as the massage progressed? Did anything noticeably change your thoughts or mood at any point?

- Were there moments in the massage where you felt more "connected" to the therapist than others? What contributed to that feeling of connection?

- What did you think the therapist was thinking about you? What made you think that?

- What made you feel that the therapist was being authentic/genuine or inauthentic?

- Were there factors other than what the therapist did or said that contributed to your response to the therapist? (For example, aspects of the studio environment, materials or equipment used, music, aromas.)

- What previous experiences (personal or professional) might have informed your response to the therapist?

\section{Client: Session 1 Additional Questions}

- What assumptions did you have about the therapist before meeting?

- What expectations did you have of the session and of massage in general before meeting?

- What was your immediate response to the therapist upon meeting? What contributed to that response?

\section{Client: Session 2 Additional Questions}

- How do you think the relationship developed since the previous session?

- Were there noticeable differences between this session and the first?

- What thoughts or feelings did you have about the therapist between sessions? How did those thoughts relate to your response to the current session?
Client: Session 3 Additional Questions

- Were there noticeable differences between this session and the last two?

- What, if any, impact do you feel the treatment sessions have had on your day-to-day life?

- What is your overall impression of the relationship you had with the therapist? What were the most important factors that contributed to that impression?

\section{Therapist Questions_-All Sessions}

- What did the client do or say that made you feel

- Understood or misunderstood?

- Helpful or unhelpful?

- Optimistic or pessimistic?

- What sources of information did you have about the client? (For example, words, tone, appearance, gestures, facial expressions, bodily responses, your own gut feeling.) Which one(s) did you rely on most significantly?

- What did you notice about the general tone of your thoughts or your mood as the massage progressed? Did anything noticeably change your thoughts or mood at any point?

- Were there moments in the massage where you felt more "connected" to the client than others? What contributed to that feeling of connection?

- Were there "ruptures" in the connection? What made you sense there had been a rupture? What did you do to address it?

- What did you think the client was thinking about you? What made you think that?

- What made you feel that the client was being authentic/genuine or inauthentic?

- What previous experiences (personal or professional) informed your response to the client?

\section{Therapist: Session 1 Additional Questions}

- What assumptions did you have about the client before meeting?

- What expectations did you have of the session and of massage in general before meeting?

- What was your immediate response to the client upon meeting? What contributed to that response?

\section{Therapist: Session 2 Additional Questions}

- How do you think the relationship developed since the previous session?

- Were there noticeable differences between this session and the first?

- What thoughts or feelings did you have about the client between sessions? How did those thoughts relate to your response to the current session?

Therapist: Session 3 Additional Questions 
- How do you think the relationship developed since the previous session?

- Were there noticeable differences between this session and the last two?
- What thoughts or feelings did you have about the client between sessions? How did those thoughts relate to your response to the current session?

- Overall, how would you describe your relationship with the client? 


\section{Appendix B. Detailed Session Breakdowns Session Durations}

\begin{tabular}{lccc}
\hline & Session 1 & Session 2 & Session 3 \\
\hline Pre-treatment Assessment & $12: 03$ & $2: 07$ & $2: 29$ \\
Treatment & $69: 37$ & $58: 51$ & $62: 08$ \\
Talk & $39: 31$ & $40: 08$ & $27: 46$ \\
Silence & $30: 06$ & $18: 43$ & $34: 22$ \\
Post-treatment Assessment $_{\text {Total }}$ & $3: 25$ & $2: 29$ & $3: 18$ \\
\hline
\end{tabular}

${ }^{a}$ Not including mid-sentence pauses or deep breathing during Proprioceptive Neuromuscular Facilitation (PNF).

\section{Session 1}

\begin{tabular}{|c|c|c|}
\hline Treatment Sequence & Actions & Topics of Discussion \\
\hline $\begin{array}{l}\text { Pre-treatment } \\
\text { assessment }\end{array}$ & $\begin{array}{l}\text { The Client completes } \\
\text { history form } \\
\text { Therapist conducts } \\
\text { postural assessment }\end{array}$ & $\begin{array}{c}\text { Background of names } \\
\text { Verbal assessment }\end{array}$ \\
\hline Treatment begins & $\begin{array}{c}\text { The Client lies face } \\
\text { down }\end{array}$ & \\
\hline Lower back/hips & Frictions, petrissage & $\begin{array}{l}\text { The Client's difficult } \\
\text { dog }\end{array}$ \\
\hline Back & $\begin{array}{l}\text { Effleurage, petrissage, } \\
\text { frictions }\end{array}$ & As above \\
\hline Shoulders & $\begin{array}{l}\text { Effleurage, frictions, } \\
\text { compressions, vibration }\end{array}$ & As above \\
\hline Interscapular & Passive stretch & As above \\
\hline Buttocks & Tapotement & Mostly silence \\
\hline Back of legs & $\begin{array}{c}\text { Tapotement, effleurage, } \\
\text { compressions, frictions, } \\
\text { vibration } \\
\text { The Client turns over }\end{array}$ & $\begin{array}{l}\text { Therapist } \\
\text { observations or } \\
\text { instructions }\end{array}$ \\
\hline Front of legs & $\begin{array}{c}\text { Effleurage, frictions, } \\
\text { petrissage } \\
\text { The Client takes toilet } \\
\text { break }\end{array}$ & Silence \\
\hline Arms & $\begin{array}{l}\text { Effleurage, frictions, } \\
\text { compressions }\end{array}$ & $\begin{array}{c}\text { The Client's bladder } \\
\text { Therapist } \\
\text { observations or } \\
\text { instructions }\end{array}$ \\
\hline Hand (R only) & Frictions & Silence \\
\hline Neck & $\begin{array}{c}\text { Effleurage, frictions, } \\
\text { passive stretch, PNF } \\
\text { stretch }\end{array}$ & $\begin{array}{l}\text { Therapist } \\
\text { observations or } \\
\text { instructions }\end{array}$ \\
\hline Scalp & Frictions & Mostly silence \\
\hline Face & Effleurage, frictions & Mostly silence \\
\hline $\begin{array}{l}\text { Post-treatment } \\
\text { assessment }\end{array}$ & $\begin{array}{c}\text { The Therapist gives } \\
\text { the Client water and a } \\
\text { protein snack }\end{array}$ & $\begin{array}{c}\text { Client education } \\
\text { Post-treatment advice }\end{array}$ \\
\hline
\end{tabular}

\section{Session 2}

\begin{tabular}{|c|c|c|}
\hline Treatment Sequence & Actions & Topics of Discussion \\
\hline $\begin{array}{l}\text { Pre-treatment } \\
\text { assessment }\end{array}$ & & Verbal assessment \\
\hline Treatment begins & $\begin{array}{c}\text { The Client lies face } \\
\text { down }\end{array}$ & \\
\hline Back & $\begin{array}{l}\text { Effleurage, petrissage, } \\
\text { frictions }\end{array}$ & $\begin{array}{l}\text { The Client's difficult } \\
\text { dog }\end{array}$ \\
\hline Lower back/hips & $\begin{array}{l}\text { Effleurage, petrissage, } \\
\text { frictions, compressions }\end{array}$ & The Client's work \\
\hline $\begin{array}{l}\text { Upper back/ } \\
\text { shoulders }\end{array}$ & $\begin{array}{l}\text { Effleurage, frictions, } \\
\text { compressions, } \\
\text { petrissage, vibration, } \\
\text { tapotement }\end{array}$ & $\begin{array}{c}\text { The Therapist's work } \\
\text { history } \\
\text { The Client's work, } \\
\text { and work history }\end{array}$ \\
\hline $\begin{array}{l}\text { Interscapular } \\
\text { ( } \mathrm{L} \text { only) }\end{array}$ & Passive stretch & $\begin{array}{c}\text { Therapist } \\
\text { observations or } \\
\text { instructions }\end{array}$ \\
\hline Back of legs & $\begin{array}{l}\text { Effleurage, frictions, } \\
\text { petrissage, vibration }\end{array}$ & $\begin{array}{l}\text { The Client's work } \\
\text { and its impact on her } \\
\text { body } \\
\text { Some silence }\end{array}$ \\
\hline Feet & $\begin{array}{l}\text { Frictions } \\
\text { The Client turns over }\end{array}$ & As above \\
\hline Front of legs & $\begin{array}{c}\text { Effleurage, frictions, } \\
\text { petrissage }\end{array}$ & The Client's work \\
\hline Feet & Frictions & As above \\
\hline Arms & Effleurage, frictions & As above \\
\hline Hands & Frictions & As above \\
\hline Neck & $\begin{array}{l}\text { Effleurage, frictions, } \\
\text { passive stretch, PNF } \\
\text { stretch }\end{array}$ & $\begin{array}{c}\text { Silence } \\
\text { Therapist } \\
\text { observations or } \\
\text { instructions }\end{array}$ \\
\hline Jaw & Frictions & As above \\
\hline $\begin{array}{l}\text { Post-treatment } \\
\text { assessment }\end{array}$ & $\begin{array}{l}\text { The Therapist gives } \\
\text { the Client water and a } \\
\text { protein snack }\end{array}$ & $\begin{array}{c}\text { Client education } \\
\text { Post-treatment advice }\end{array}$ \\
\hline
\end{tabular}


Session 3

\begin{tabular}{|c|c|c|}
\hline Treatment Sequence & Actions & Topics of Discussion \\
\hline $\begin{array}{l}\text { Pre-treatment } \\
\text { assessment }\end{array}$ & & Verbal assessment \\
\hline Treatment begins & $\begin{array}{c}\text { The Client lies face } \\
\text { down }\end{array}$ & \\
\hline Back & Effleurage & $\begin{array}{l}\text { The Client's } \\
\text { boyfriend } \\
\text { The Client's brother }\end{array}$ \\
\hline Lower back/hips & $\begin{array}{l}\text { Frictions, } \\
\text { compressions, } \\
\text { effleurage }\end{array}$ & As above \\
\hline $\begin{array}{l}\text { Upper back/ } \\
\text { shoulders }\end{array}$ & $\begin{array}{l}\text { Frictions, effleurage, } \\
\text { compressions, } \\
\text { petrissage, vibration }\end{array}$ & $\begin{array}{c}\text { Therapist } \\
\text { observations or } \\
\text { instructions } \\
\text { The Client's recent } \\
\text { activity and its impact } \\
\text { on her body } \\
\text { The Therapist's } \\
\text { speedboating } \\
\text { experience }\end{array}$ \\
\hline Neck & Petrissage, frictions & As above \\
\hline Back of legs & $\begin{array}{l}\text { Effleurage, frictions, } \\
\text { petrissage }\end{array}$ & $\begin{array}{l}\text { The Therapist's } \\
\text { speedboating } \\
\text { experience } \\
\text { Therapist } \\
\text { observations or } \\
\text { instructions } \\
\text { Some silence }\end{array}$ \\
\hline Feet & $\begin{array}{l}\text { Frictions } \\
\text { The Client turns over }\end{array}$ & As above \\
\hline Front of legs & $\begin{array}{l}\text { Effleurage, petrissage, } \\
\text { frictions }\end{array}$ & Silence \\
\hline Feet & Frictions & As above \\
\hline Arms & Effleurage, frictions & Silence \\
\hline Chest (R only) & Frictions, compressions & $\begin{array}{l}\text { Therapist } \\
\text { observations or } \\
\text { instructions }\end{array}$ \\
\hline Hands & Frictions & Silence \\
\hline Neck & $\begin{array}{c}\text { Effleurage, frictions, } \\
\text { PNF stretch, passive } \\
\text { stretch }\end{array}$ & $\begin{array}{l}\text { Therapist } \\
\text { observations or } \\
\text { instructions } \\
\text { Silence }\end{array}$ \\
\hline Face & Effleurage & Silence \\
\hline Scalp & Frictions & Silence \\
\hline $\begin{array}{l}\text { Post-treatment } \\
\text { assessment }\end{array}$ & $\begin{array}{l}\text { The Therapist models } \\
\text { self-massage, gives } \\
\text { the Client water and a } \\
\text { protein snack }\end{array}$ & $\begin{array}{l}\text { Client education } \\
\text { Post-treatment advice }\end{array}$ \\
\hline
\end{tabular}

